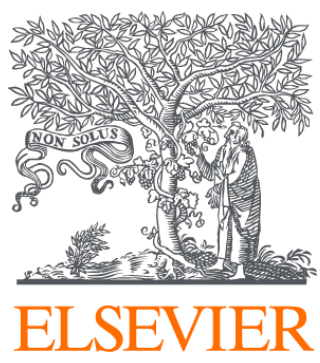

Since January 2020 Elsevier has created a COVID-19 resource centre with free information in English and Mandarin on the novel coronavirus COVID-

19. The COVID-19 resource centre is hosted on Elsevier Connect, the company's public news and information website.

Elsevier hereby grants permission to make all its COVID-19-related research that is available on the COVID-19 resource centre - including this research content - immediately available in PubMed Central and other publicly funded repositories, such as the WHO COVID database with rights for unrestricted research re-use and analyses in any form or by any means with acknowledgement of the original source. These permissions are granted for free by Elsevier for as long as the COVID-19 resource centre remains active. 


\section{Letter to the Editor: Contact lens practice in the time of COVID-19}

Dear Editor,

This is in reference to the article titled "Contact lens practice in the time of COVID-19" by Zeri F and Naroo SA published in the current issue of the Contact Lens and Anterior Eye journal [1]. The authors have extensively reviewed the practice of ophthalmic contact lens (CL) during novel coronavirus disease 2019 (COVID-19) outbreak. We would hereby like to suggest that the Figure 2 which should be replaced by a one more standard for referencing. As we all know that patient-to-ophthalmologist transmission of the new strain of coronavirus is a big threat to ophthalmic practice. Infectious droplets and body fluids (such as tears, conjunctival secretions, saliva) can easily contaminate the human conjunctival epithelium [2], so novel coronavirus may be transmitted through eye touching or rubbing. Whenever ophthalmologists and optometrists are examining patients, they should be fully gowned with protective suit and N95 respirator as well as masks, gloves and goggles $[3,4]$. At the same time, face protection, eye protection, nasal and oral mucosa protection as well as outer ear and hair protection are inevitably necessary. We know Figure 2 showing a large clear plastic sheet for precaution, however, in Figure 2, these precautions appear insufficient, including lack of medical hat for hair protection from droplets, facial masks and goggles for eye protection. Furthermore, CL practitioners and practitice staff with potential conditions of flu-like symptoms should not attend work. In Tianjin Eye Hospital, all the CL practitioners and staff are required to measure and report their own body temperatures, any symptoms such as fever, chills, sore throat, cough, sneeze, vomiting, diarrhoea or pneumonia as well as travel histories. Even reporting of their family members in required. Only strict infection control measures are implemented, the person-to-person transmission routes of COVID-19 in CL practice and hospitals would be blocked as soon as possible.

\section{Author contributions}

Hongxia Wang and Wenjun Kong contributed equally to the manuscript as co-first author.

\section{Declaration of Competing Interest}

No conflict of interest to be declared.

\section{Role of the funder/sponsor}

None of the funders had a role in the preparation, review, or approval of the manuscript; and decision to submit the manuscript for publication.

\section{References}

[1] F. Zeri, S.A. Naroo, Contact lens practice in the time of COVID-19, Cont Lens Anterior Eye (March) (2020), https://doi.org/10.1016/j.clae.2020.03.007 pii: S13670484(20)30050-3, [Epub ahead of print].

[2] C.W. Lu, X.F. Liu, Z.F. Jia, 2019-nCoV transmission through the ocular surface must not be ignored, Lancet 395 (2020) e39.

[3] A.Y. Yu, R. Tu, X. Shao, A. Pan, K. Zhou, J. Huang, A comprehensive Chinese experience against SARS-CoV-2 in ophthalmology, Eye Vis (Lond) 7 (2020) 19, https:// doi.org/10.1186/s40662-020-00187-2 eCollection 2020.

[4] T.H.T. Lai, E.W.H. Tang, S.K.Y. Chau, K.S.C. Fung, K.K.W. Li, Stepping up infection control measures in ophthalmology during the novel coronavirus outbreak: an experience from Hong Kong, Graefes Arch Clin Exp Ophthalmol (March) (2020), https://doi.org/10.1007/s00417-020-04641-8 [Epub ahead of print].

\section{Hongxia Wang \\ Shanghai Aier Eye Hospital, Shanghai, China}

Wenjun Kong

Beijing You'an Hosptial, Capital Medical University, Beijing, China

Wei Zhang, Qian Fan*

Tianjin Eye Hospital and Eye Institute, Tianjin Key Lab of Ophthalmology and Visual Science, Nankai University Affiliated Eye Hospital, Clinical College of Ophthalmology, Tianjin Medical University, Tianjin, China E-mail address: fanqian2002_yahoo@126.com (Q. Fan).

\footnotetext{
* Corresponding author at: Tianjin Eye Hospital and Eye Institute, Tianjin Key Lab of Ophthalmology and Visual Science, Clinical College of Ophthalmology, Tianjin Medical University, No. 4 Gansu Road, He-ping District, Tianjin 300020, China. 